\title{
The Use of Non-Surgical Injectable Procedures Among Transgender Communities
}

\author{
PATRICKJ. KELLY, MPH ${ }^{1}$ \\ ${ }^{1}$ Department of Social and Behavioral Sciences, College of Public Health, Temple University \\ Correspondence: patrick.kelly@,temple.edu (Patrick J. Kelly)
}

\begin{abstract}
Each year, millions of Americans undergo non-surgical injectable procedures to rejuvenate, add volume, and shape the face. These minimally invasive procedures are routinely performed by licensed medical professionals including plastic surgeons and dermatologist using FDA approved substances. Because these procedures alter physical appearance, non-surgical injectable procedures may compliment gender-affirming procedures that some transgender (trans) individuals undergo to affirm their gender identity. However, severe marginalization and discrimination towards trans communities often leaves formalized medical settings inaccessible. Indeed, anecdotal reporting and medical literature indicate that there is a market for performing these procedures in unregulated medical settings using dangerous non-FDA approved materials outside of safe medical settings. The practice, referred to often as "pumping", happens particularly within trans communities, largely because of social and political factors that make formalized medicine inaccessible. Even though pumping can be an affirming experience for trans individuals, an unfortunate number of those who undergo non-FDA approved non-surgical injectable procedures experience uncorrectable adverse outcomes including death. Despite indications that trans individuals may benefit from FDA approved non-surgical injectable procedures and the growing literature detailing irreversible outcomes of non-FDA approved non-surgical injectable procedures, the medical and scientific communities do not fully understand how trans individuals conceptualize and engage with non-surgical injectable procedures. A brief overview of factors that may contribute to this underground practice is presented in this narrative review and synthesized to inform suggestions for future socio-behavioral and epidemiological approaches that ultimately aim to expand access to safe and affirming bealthcare settings for trans individuals.
\end{abstract}

\section{Introduction}

Non-surgical injectable procedures performed by board certified medical professionals using FDA approved substances add volume, contour, and smoothness to areas of the face while offering near immediate results. ${ }^{1,2}$ This method of addressing appearance related concerns of the face are often in part desired because recipients can achieve facial rejuvenation without the use of surgically invasive techniques. ${ }^{3}$ These procedures are also quite popular; in 2019, approximately 10.4 million non-surgical injectable procedures were performed, accounting for nearly $64 \%$ of minimally invasive aesthetically related procedures. ${ }^{4}$ Annually, the number of women who receive these routine procedures outnumbers men. ${ }^{4}$ However, little is understood about the use of non-surgical injectable procedures within transgender (trans) communities.

Trans individuals, whose United States population is estimated at 1.4 million, conceptualize and often physically embody a gender identity and or gender expression different from a gender as signed at birth. ${ }^{56}$ 
Transitioning (i.e. the process of modifying characteris tics to affirm an internal sense of gender identity) is a process that differs for each person of trans experience. Many trans people socially transition via the actualization of correct personal pronouns, name changes, and coming out to others as trans. Moreover, some, but not all, trans individuals, desire, seek, and benefit from medical interventions that affirm gender identity. ${ }^{6}$ Non-surgical injectable procedures may offer a quick and safe adjunct to other gender-affirming procedures, like hormone replacement therapy, when performed by licensed medical professionals using FDA approved substances.

Even though millions of people safely receive non-surgical injectable procedures annually, systematic data about the use of non-surgical injectable procedures by trans individuals is largely nonexistent. Recent reports suggest that some trans individuals turn to unlicensed paraprofessionals for injections with substances not approved for use by the United States Food and Drug Administration (FDA) such as silicone and cas tor oil- often because of barriers to accessible and affordable healthcare. ${ }^{7-11}$ This practice, colloquially termed "pumping" with "fillers", has been reported across United States locales including Chicago, Los Angeles, San Francisco, Washington D.C., Puerto Rico and other countries, particularly in Asia. ${ }^{12-18}$ Lack of accessible and affordable healthcare services, transphobia in medicine, medical racism, and poverty often push people to pursue this practice outside of regulated medical settings.7,8 An unfortunately large body of evidence has documented adverse outcomes experienced by individuals who undergo these underground procedures. ${ }^{19}$ Yet, this practice has received little attention from medical researchers.

\section{Adverse Health Outcomes}

FDA approved non-surgical injectable procedures performed by medically licensed professionals are low risk. Conversely, non-FDA approved non-surgical injectable procedures often result in undesirable and health-threatening outcomes such as local irritation, systemic health complications, and death. ${ }^{19-27}$ Complications that present great medical concern include post-injection skin bumps, allergic reactions, and pathologic conditions that threaten the circulatory and respiratory systems. Moreover, because these procedures are done by individuals who lack the technical craft of licensed professionals, the results of non-FDA approved non-surgical injectables often compromise self-image - a typically elevated concern among trans individuals. ${ }^{28}$ Little can be done to redress serious appearance concerns stemming from nonFDA approved non-surgical injectable procedures, as reconstructive interventions to address complications are technically cumbersome and pose great challenges to patients and their surgeons. ${ }^{28}$

In response to mounting evidence detailing troubling outcomes of injectable procedures for aesthetic purposes, the FDA recommended against the use of injectables in the body, particularly with silicone, in 1991..$^{29}$ Since then, the federal agency has issued consumer advisories that underscore the harms injecting hazardous materials into the body causes. ${ }^{30}$ Pumping has also been criminalized; unlicensed injectors have been prosecuted for the death of those they have injected. A notorious case was tried in Philadelphia over the deaths caused by the injections performed by an infamous paraprofessional who worked under the pseudonym "Black Madam". ${ }^{31}$ Notwithstanding these known risks and advisories, pumping is often an affirming experience for trans individuals, especially amongst those who face extreme marginalization and abundant political and social barriers to healthcare.7,8,18,32 Unpacking contextual considerations that may contribute to this practice is a necessary step towards evidence-based, person-centered research with trans individuals who engage in this practice. 


\section{Marginalization and Healthcare Access}

The Crenshaw theory of intersectionality offers a framework in which race, class, wealth, sexual orientation, immigration status, religion, ability, and geographic locale multiplicatively interact and contribute to experiences of marginalization among trans individuals. ${ }^{33}$ Macrolevel influences, such as policies that complicate name changes, and microlevel factors, such as interpersonal transphobia, target identities and often result in reduced social and economic capital, exclusionary and harmful healthcare experiences, and reduced overall well-being. ${ }^{34,35}$ Trans communities, especially trans communities of color, the undocumented, and those whose gender expression exists beyond the binary of "male" and "female", have been subject to decades of stigmatization and institutionalized discrimination in the United States that threaten gender-affirmation. ${ }^{36}$ Rampant marginalization and experiences of minoritization partially account for the alarming health disparities that manifest on a population-based scale as health inequities that trans communities experience. ${ }^{34}$ For example, rates of risk behavior are elevated among trans communities and experiences of marginalization may account for this; a pressing desire to affirm ones gender as a rejection of marginalization supersedes the harms some health behaviors, such as pumping, present. ${ }^{37}$

Marginalization and discrimination reduce access to healthcare. Compared to the alternative, non-FDA approved non-surgical injectables are more accessible for people who experience economic hardship. Of those included in the National Transgender Discrimination Survey who were employed, the vast majority $(90 \%)$ reported mistreatment at work, $55 \%$ reported loss of job opportunities because of workplace bias, and $26 \%$ lost employment because of reasons explicitly tied to gender. ${ }^{35}$ Respondents were four times more likely to have a household income below $\$ 10,000$ than the general population and $19 \%$ reported ever being homeless. ${ }^{35}$ These disparities are widened when considering racial identity; trans communities of color experience unemployment rates four times greater than the U.S. general population. ${ }^{35}$ Among insured participants of the 2015 U.S Transgender Survey, the largest national survey of trans people in the United States to date, one in four respondents experienced difficulty accessing gender-affirming care. ${ }^{34}$ One in two individuals who pursued gender-affirming medical care were denied insurance coverage entirely. ${ }^{34}$ So, individuals may pursue pumping because it is simply more financially accessible than regulated medical procedures.

Even though many academic medical settings and health systems are making strides to honor and respect trans identities, these institutions have a lengthy transphobic history. ${ }^{36} \mathrm{~A}$ recent literature review concluded that medical education inadequately prepares student doctors with the medical knowledge, and cultural humility, to appropriately care for trans patients. ${ }^{38}$ Trans individuals regularly disclose having to teach medical providers about their medical care and some trans individuals are refused healthcare because of their identity. ${ }^{34}$ Thus, it is likely that trans individuals may avoid formalized medical settings and instead opt for informal settings where there is greater assurance that identies are validated and respected. These sociocultural considerations may contribute to the willingness of trans individuals to interact with informal medicine including non-FDA approved non-surgical injectable procedures.

Pumping can provide some trans individuals with protection and income. Some trans people pursue gender-affirming procedures to "pass" as a cisgender person; said another way - some trans people do not want it to be obvious that they are trans and may pursue aesthetically related procedures to ensure this. ${ }^{36}$ For some, passing provides protection from violence against trans communities which is especially heightened among trans women of color..$^{39}$ Equally notable are people engaged in sex work who may undergo potentially harmful procedures to increase work prospects, ensure safety while working via passing, and bolster economic opportunity. Efforts to better understand engagement with non-FDA approved non-surgical injectable procedures must be situated within an understanding that these aes thetic 
procedures, although risky, protect people from violence and beget economic opportunity for communities that systemically experience disenfranchisement. Qualitative inves tigations have echoed the call for increased attention to social factors and realities that may indirectly contribute to engagement with non-FDA approved non-surgical injectables in this population. ${ }^{78}$ Thus, recommendations for future investigations mustbalance the goal of reducing harms associated with this underground practice and the reality that for many trans people, pumping can be affirming and is often a safeguard against marginalization, violence, and financial distress.

\section{Recommendations}

Understanding of demographic, psychosocial, and decision-making processes related to engagement with non-FDA approved non-surgical injectable procedures by trans individuals is in its infancy. Accordingly, the U.S. Food and Drug Administration and the Society for Public Health Education have called for research into this topic in light of mounting evidence that these procedures pose myriad harms to trans individuals. ${ }^{30,40}$ As such, mixed-method epidemiological investigations should be employed to further assess the scope of this practice. Semi-structured and narrative interviews with individuals who have had non-surgical injectable procedures and with those who have performed these procedures would offer rich insight into a practice not well understood by medical researchers. To add rigor to approaches, inves tigators would do well to utilize validated measures, as this will enable comparisons across literature and potentially validate previously unused measures with a population the National Academy of Medicine characterized as systematically under-engaged in research. ${ }^{41}$

The paucity of epidemiologic data regarding the use of these procedures among trans communities underscores the need for systematic data collection efforts about the amount of procedures performed and procedural outcomes. Institutions that provide psychosocial and medical services to trans patients, LGBT community health organizations, dermatologists, and plastic surgeons should partner to establish a cohort of trans individuals who have had non-FDA approved non-surgical injectable procedures to advance the methodologic rigor applied to monitor and understand adverse health outcomes. Medical and scientific communities should create a succinct Behavioral Risk Factor Surveillance System module as a complement to existing modules available for state use to structurally document the occurrence of these procedures. Findings of these collective efforts would aid in the development of robust medical guidelines for clinical use in managing the adverse outcomes of these procedures that could be incorporated into the internationally referenced Standards of Care for the Health of Transsexual, Transgender, and Gender Nonconforming People. ${ }^{6}$

Community based participatory research is a fundamentally necessary approach to successful research with trans communities that must be adopted to achieve these recommendations. The inclusion of trans individuals in investigative efforts can empower communities that have been traditionally viewed as objects of study rather than keystone collaborators who provide invaluable insights and share in the research process. ${ }^{42}$ As such, investigators should liaise with LGBTQ organizations to identify key stakeholders whose milieu would result in the gathering of pertinent information to explicate this culturally driven practice and inform future investigations and recommendations to protect and better trans lives. Partnerships with members of the ball community, a cultural hub for LGBTQ individuals, could be directly engaged in research centering trans communities, specifically around sensitive, underground practices. To guide these efforts, the National Institutes of Health Sexual and Gender Minority Research Office could spearhead recommended inves tigations to better understand engagement with non-surgical injectable procedures among trans communities. 
In tandem with aforementioned research objectives, additional efforts to improve overall healthcare access for trans communities are highly indicated. Expanding access to affordable and accessible genderaffirming healthcare should reduce engagement with informal, and often risky, means of transitioning. Actions to address differential access to formalized medical settings for trans individuals must include diversifying the procedures insurance companies consider gender-affirming and a total elimination of health insurance plans that exclude trans related healthcare services. Contrary to recent rule changes to Section 1557 of the Patient Protection and Affordable Care Act that aim to restrict access to healthcare for trans individuals, federal and state policy should protect and afford trans individuals equitable access to healthcare, including safe and trans-inclusive services. ${ }^{43}$ Furthermore, healthcare professionals must receive extensive trans-inclusive training as this can lead to a reduction in the stigma and discrimination trans individuals face when seeking care. ${ }^{44}$

\section{Conclusion}

The vast majority of non-surgical injectable procedures are safely performed by licensed professionals. However, a small percentage of people engage with non-FDA approved non-surgical procedures within trans communities despite known health and legal risks the practice poses. A complex interplay of social, political, intra- and interpersonal factors rooted in social determinants of health and social norms around gender expression may contribute to this practice among trans communities. It is pertinent that investigations focused on this practice are undertaken and that it remains a priority for all researchers to center trans experiences and avoid further reducing access to care for this already underserved population.

\section{Disclosures and Conflicts of Interest}

The author declares that there is no conflict of interest.

\section{References}

1. The American Society for Aesthetic Plastic Surgery. Fillers [Internet]. 2019. [cited 2020 March 15]. Available from: https://www.smartbeautyguide.com/procedures/injectables/fillers/.

2. Sarwer DB. Body image, cosmetic surgery, and minimally invasive treatments. Body Image. 2019;31:302-308.

3. Devgan L, Singh P, Durairaj K. Minimally invasive facial cosmetic procedures. Otolaryngol Clin North Am. 2019;52(3):443-59.

4. American Society of Plastic Surgeons. American Society of Plastic Surgeons national clearinghouse of plastic surgery procedural statistics-2019 [Internet]. 2020. [cited 2020 August 14] Available from: https:/ / www.plasticsurgery.org/documents/News/Statistics/2019/plastic-surgery-statistics-fullreport-2019.pdf.

5. Flores AR, Herman JL, Gates GJ, Brown TNT. How Many Adults Identify as Transgender in the United States? [Internet]. 2016. [cited 2020 March 15]. Available from: https://williamsinstitute.law.ucla.edu/wp-content/uploads/How-Many-Adults-Identify-asTransgender-in-the-United-States.pdf.

6. The World Professional Association for Transgender Health. Standards of care for the health of transsexual, transgender, and gender nonconforming people [Internet]. 2011 [cited 2020 March 15]. Available from: www.wpath.org.

7. Wallace PM, Rasmussen S. Analysis of adulterated silicone: Implications for health promotion. Int J Transgen. 2010;12(3):167-175. 
8. Wallace PM. Finding self: A qualitative study of transgender, transitioning, and adulterated silicone. Heal Educ J. 2010;69(4):439-446.

9. Nett D. For trans women, silicone "pumping" can be a blessing and a curse. National Public Radio. 2019, Sep 1.

10. Murray RL. Some transgender women pay a high price to look more feminine. The New York Times. 2011 Aug 21.

11. Edgar J. Silicone injections are deadlier than ever. Harpers Bazaar. 2018 Jan 30

12. Idrus NI, Hymans TD. Balancing benefits and harm: Chemical use and bodily transformation among Indonesia's transgender waria. Int J Drug Policy. 2014;25(4):789-797.

13. Kenagy GP, Bostwick WB. Health and social service needs of transgender people in Chicago. Int J Transgenderism. 2005;8(3):57-66.

14. Poompruek P, Boonmongkon P, Guadamuz TE. "For me... it's a miracle": Injecting beauty among kathoeis in a provincial Thai city. Int J Drug Policy. 2014;25(4):798-803.

15. Reback JC, Simon AP, Bemis CC, Gatson B. The Los Angeles Transgender health study: Community report [Internet]. 2001 [cited March 15]. Available from: https:/ / static1.squarespace.com/static/5a1dda626957daf4c4f9a3bb/t/5acfa341562fa7b5ec5db914 /1523557236754/Reback_LA+Transgender+Health+Study_2001.pdf.

16. Wilson E, Rapues J, Jin H, Fisher Raymond H. The use and correlates of illicit silicone or "fillers" in a population-based sample of transwomen, San Francisco, 2013. J Sex Med. 2014;11(7):1717-24.

17. Xavier JM, Bobbin M, Singer B, Budd E. A needs asses sment of transgendered people of color. Int J Transgenderism. 2005;8(3):31-47.

18. Padilla MB, Rodríguez-Madera S, Ramos Pibernus AG, Varas-Díaz N, Neilands TB. The social context of hormone and silicone injection among Puerto Rican transwomen. Cult Health Sex. 2018;20(5):574-90.

19. Styperek A, Bayers S, Michael B; Beer K. Nonmedical-grade injections of permanent fillers medical and medicolegal considerations. J Clin Aesthet Dermatol. 2014;6(4):22-9.

20. Leonardi NR, Compoginis JM, Luce EA. Illicit cosmetic silicone injection: A recent reiteration of history. Ann Plast Surg. 2016;77(4):485-90.

21. Narins RS, Beer K. Liquid injectable silicone: A review of its history, immunology, technical considerations, complications, and potential. Plast Reconstr Surg. 2006;118:77S-84S.

22. Agrawal N, Altiner S, Mezitis NHE, Helbig S. Silicone-induced granuloma after injection for cosmetic purposes: A rare entity of calcitriol-mediated hypercalcemia. Case Rep Med. 2013;2013:807292.

23. Hariri LP, Gaissert HA, Brown R, et al. Progressive granulomatous pneumonitis in response to cosmetic subcutaneous silicone injections in a patient with HIV-1 infection: Case report and review of the literature. Arch Pathol Lab Med. 2012;136(2):204-7.

24. Gaber Y. Secondary lymphoedema of the lower leg as an unusual side-effect of a liquid silicone injection in the hips and buttocks. Dermatology. 2004;208(4):342-4.

25. Tachamo N, Donato A, Timilsina B, Nazir S, Lohani S, Dhital R, et al. Hypercalcemia associated with cosmetic injections: A systematic review. Eur J Endocrinol. 2018;178(4):425-30.

26. Visnyei K, Samuel M, Heacock L, Cortes JA. Hypercalcemia in a male-to-female transgender patient after body contouring injections: A case report. J Med Case Rep. 2014;8:71.

27. Ohnona J, Durand P, Amegnizin JL, Kerrou K. Silicone granuloma in the buttocks incidentally detected by 18F-FDG PET/CT 30 years after free liquid silicone injections. Clin Nucl Med. 2016;41(6):492-493.

28. Murariu D, Holland MC, Gampper TJ, Campbell CA. Illegal silicone injections create unique reconstructive challenges in transgender patients. Plast Reconstr Surg. 2015;135(5):932e-933e.

29. Coleman SR. Injectable silicone returns to the United States. Aesthet Surg J. 2001;21:576-8.

30. United Stated Food and Drug Administration. Consumer updates- TheFDA warns againstinjectable silicone for body contouring and enhancement [Internet]. 2017 [cited 2020 March 15] Available from: 
https:/ / www.fda.gov/medical-devices / safety-communications/fda-warns-against-use-injectablesilicone-body-contouring-and-enhancement-fda-safety-communication.

31. Slobodzian J. "Black Madam" convicted in injection death. The Philadelphia Inquirer. March 9, 2015.

32. Pollock L, Silva-Santisteban A, Sevelius J, Salazar X. 'You should build yourself up as a whole product': Transgender female identity in Lima, Peru. Glob Public Health. Aug-Sept2016;11(7-8):98193.

33. Crenshaw K. Demarginalizing the intersection of race and sex: A black feminist critique of antidiscrimination doctrine, feminist theory and antiracist politics. Univ Chic Leg Forum. 1989;1989(1):137-67.

34. National Center for Transgender Equality. The Report of the U.S. Transgender Survey. [Internet]. 2016. [cited 2020 March 16]. Available from: https:/ / transequality.org/sites/default/ files/docs/usts/USTS-Executive-Summary-Dec17.pdf.

35. Grant JM, Mottet LA, Tanis J, Harrison J, Herman J, Keisling M. Injustice at every turn: A report of the national transgender discrimination survey. Vol 11. Washington, D.C.; 2011.

36. Lester C. Trans like Me: Conversations for All of Us. New York: Seal Press; 2018.

37. Sevelius JM. Gender affirmation: A framework for conceptualizing risk behavior among transgender women of color. Sex Roles. 2013;68(11-12):675-89.

38. Korpaisarn S, Safer JD. Gaps in transgender medical education among healthcare providers: A major barrier to care for transgender persons. Rev Endocr Metab Disord. 2018;19(3):271-5.

39. Human Rights Campaign. Violence Against the Transgender Community in 2018 [Internet]. 2018 [cited 2020 March 15]. Available from: https://www.hrc.org/resources/violence-against-thetransgender-community-in-2018.

40. Society for Public Health Education. Health Impact of Adulterated Silicone on Transgender Health [Internet]. 2012 [cited 2020 March 15]. Available from: https://www.sophe.org/wpcontent/uploads/2017/01/transgender_policy_approved_letterhead.pdf.

41. Institute of Medicine (US) Committee on Lesbian, Gay, Bisexual and Transgender Health Issues and Research Gaps and Opportunities. The Health of Lesbian, Gay, Bisexual, and Transgender People: Building a Foundation for Better Understanding. Washington, D.C.: National Academies Press (US); 2011.

42. Wallerstein NB, Duran B. Using community-based participatory research to address health disparities. Health Promot Pract. 2006;7(3):312-23.

43. U.S. Department of Health and Human Services. HHS Finalizes Rule on Section 1557 Protecting Civil Rights in Healthcare, Restoring the Rule of Law, and Relieving Americans of Billions in Excessive Costs [Internet]. 2020. [cited 2020 Aug 7]. Available from: https:/ / www.hhs.gov/about/ news/2020/06/12/hhs-finalizes-rule-section-1557-protecting-civilrights-healthcare.html.

44. Nolan IT, Blasdel G, Dubin SN, Goetz LG, Greene RE, Morrison SD. Current state of transgender medical education in the United States and Canada: Update to a scoping review. J Med Educ Curric Dev. 2020;7:1-13.

\section{Statement of Contributions}

PJK is the sole author of this work and therefore contributed across all stages of development. 